\title{
Integrated water resource management in complex systems: How the catchment management strategies seek to achieve sustainability and equity in water resources in South Africa\#
}

\author{
Sharon Pollard* and Derick du Toit \\ Association for Water \& Rural Development (AWARD), Private Bag X 420, Acornhoek 1360, South Africa
}

\begin{abstract}
It is increasingly evident amongst practitioners and academics alike that the management approaches of the past have failed to deal adequately with the challenges posed by complex and rapidly changing systems. Indeed the call for integrated approaches such as those embodied in integrated water resource management (IWRM) reflects such concerns. This is because these systems are characterised by complexity in which an understanding of linkages, multiple drivers and unpredictable outcomes is critical. It is also widely recognised that the management of such systems requires an iterative, 'learning-by-doing' approach that is reflexive in nature and builds learning into the next management cycle. We suggest that any attempt to define and implement viable and effective governance of water resources, as well as rehabilitation measures, requires understanding that catchments are complex systems showing the aforementioned characteristics. As a corollary, an adaptive management approach appears best suited to such conditions.

In this paper we argue that South Africa's highly-acclaimed National Water Act and associated policy documents such as the National Water Resource Strategy is an example of a policy document that reflects this thinking, as is evident in the guidelines for the development of catchment management strategies which are introduced and described. These offer a framework for the development of a holistic, systems understanding which is strategic and adaptive. In particular, under such a framework, we select the two cornerstones of the Act - sustainability and equity - to explore this theme. We show that under such a framework ensuring that both these principles are achieved is not through one simplistic management action but through an integrated, systems approach. The development of strategies is driven by principles which help one to navigate issues that emerge in complex systems in a flexible way. Visioning and scenarios offer important management tools for establishing a hierarchy of actions that can achieve the overarching principles and that can accommodating change. In complex systems, the users must be part of deriving management solutions since this is where and how they learn. Self-organisation, identity and embeddedness are all essential characteristics of building resilience in a catchment system.
\end{abstract}

Keywords: complex systems, integrated water resource management, catchment management strategies, sustainability, equity

\section{Introduction}

South Africa's highly-acclaimed National Water Act (Act 36 of 1998) provides the foundation for a new and fundamentally different way of managing the nation's water resources. Together with the White Paper for National Water Policy (which sets out 28 principles; DWAF 1997), it challenges the policies and values of the past by framing water resource management within the context of two fundamental principles: equity and sustainability (RSA 1998). These principles are strongly transformatory in nature, seeking to move towards integration, redistribution and equity in allocation, sustainable use, resource protection and participation (see preamble). Moreover, the importance of international needs is also recognised. Equally ground-breaking in nature, the Water Services Act (Act 108 of 1997) which provides for the rights to basic water supply and sanitation,

Revised version. Originally presented at the International Conference on Integrated Water Resource Management (IWRM) entitled: Lessons from Implementation in Developing Countries which took place from 10 to 12 March 2008 in Cape Town, South Africa, at the Cape Town International Convention Centre.

* To whom all correspondence should be addressed.

푱 +2715 793 7500; fax: +2715 793750 ;

e-mail: sharon@award.org.za recognises that although the provision of water and sanitation services is an activity distinct from the overall management of water resources, it 'must be undertaken in a manner consistent with the broader goals of water resource management'. These are provided for by the National Water Act.

Central to the re-orientation embodied in the National Water Act (henceforth referred to as the Act) is the concept of integrated water resource management (IWRM). In this regard, the Act explicitly recognises 'the need for the integrated management of all aspects of water resources'. The Department of Water Affairs \& Forestry (DWAF 2003a) defines IWRM as 'a philosophy, a process and a management strategy to achieve sustainable use of resources by all stakeholders at catchment, regional, national and international levels, while maintaining the characteristics and integrity of water resources at the catchment scale within agreed limits' (see also GWP 2002, Jones et al. 2006). In its entirety IWRM therefore aims to strike a balance between the use of resources for livelihoods and its protection for future generations, whilst promoting social equity, environmental sustainability and economic efficiency (DWAF, 2004 a). It also draws on a rights discourse (see Box 1). Another fundamental change that accompanied the policy overhaul was the management of water resources on a catchment basis. Indeed the Act notes that the National Water resource Strategy (NWRS) must provide the framework within which water will be managed at regional or catchment level, in defined water management areas. 


\section{Box 1: A rights approach}

The Bill of Rights also gives all South Africans the right to an environment that is "not harmful to their health or well-being", as well as the right to have the environment protected for the benefit of present and future generations. It is, therefore, the duty of the Government to make sure that water pollution is prevented, that there is sufficient water to maintain the ecological integrity of our water resources, and that water conservation and sustainable, "justifiable economic and social development" are promoted. This section of the Constitution moves us away from the old approach that pitted environmental goals against economic and development ones, and requires, instead, that they be integrated (National Water Policy, DWAF, 1997)

It also directs the Strategy to "promote the management of catchments within a water management area in a holistic and integrated manner'.

At about the same time that the Act was being developed, there was an increasing recognition amongst practitioners and academics alike that the natural resource management approaches of the past were failing to deal adequately with the challenges posed by complex and rapidly changing systems (see for example Gunderson et al., 1995; Holling, 2000; Kinzig et al., 2000; Holling, 2001; Folke et al., 2002; Holling et al., 2002). Indeed the call for integrated approaches such as those embodied in IWRM reflects such concerns (see for example Munro, 1995; McKay, 1996; Görgens et al., 1998; Global Water Partnership 2002; Penning de Vries et al., 2002; King and Brown, 2006).

In this paper we seek to illustrate how the Act, together with the National Water Resource Strategy and the more detailed catchment management strategies provide an enabling policy mileu for managing catchments as complex, linked systems. This is evident in the newly-published guidelines for the development of catchment management strategies which are introduced and described in this paper (DWAF, 2007 a). These offer a framework for the development of a holistic, systems understanding which is both strategic and adaptive. In particular we select the two cornerstones of the Act - sustainability and equity - to explore this theme. We hope to demonstrate that, under such a framework, ensuring that both these principles are achieved requires an integrated, systems approach. We start with a brief overview of the emerging discourse on complexity and the implications that this has for management of water resources on a catchment basis. We then go on to introduce the catchment management strategies and to demonstrate how integration, reflection and learning are essential elements for achieving these principles.

\section{Catchments as complex, linked systems}

We suggest that both the water resource statutes and policies provide an enabling environment for strategic, integrated water resource management in complex systems. This intent is to be captured by the catchment management strategies - or CMSs - to be developed by each of the water management areas in South Africa. In support of this, the Department of Water Affairs \& Forestry (DWAF) has recently published guidelines for the development of these catchment management strategies (DWAF, 2007 a). Nonetheless, prior to describing these, it is opportune to examine the concept of complexity and why it is important for IWRM. The following overview cannot purport to provide an extensive review for those interested in complexity and systems theory and readers are referred to the cited literature. Much of this thinking emanates from a programme designed to examine complexity and resilience within the context of water resources in the Sand River Catchment.

Catchments comprise linked social and ecological systems. It is widely recognised that each of these systems is complex in their own right, and it can be appreciated that additional complexity is added once their interactions are considered. Within the context of water resource management in South Africa, the concept of complexity is not a new one. Indeed, South Africa's policies and statutes make specific reference to complexity and, as a corollary, to the need for integration. The White Paper (DWAF, 1997) recognises the complexity of various socioeconomic and ecological interactions in its calls for integrated approaches to water management. Moreover although DWAF has no direct jurisdiction over land use management, Principle 18 notes that 'since many land uses have a significant impact upon the water cycle, the regulation of land use shall, where appropriate, be used as an instrument to manage water resources within the broader integrated framework of land use management.' The NWRS dedicates a significant portion of the first chapter to the need for IWRM in complex systems. Indeed it explicitly states that 'freshwater is a complex ecological system that has a number of dimensions'. These include the inter-linkages between various components and the need to manage these links and relationships, such as those between surface water and groundwater; quantity and quality; runoff from the land, infiltration and evaporation; demand, supply and discharge, and land-use/water linkages. The linkages between sustainability and the ability to ensure basic water supply is clearly recognised in the Water Services Act (S11). These linkages operate across different scales both in space and time. Taking an even broader view, water has not only an ecological face but also socio-economic, political and institutional facets that need to be managed. In South Africa particular emphasis must be placed a full understanding of its importance for social and economic development.

Colloquially, 'complexity' has a loose meaning, differing somewhat from the more conceptual meaning explained below. Complexity theory arose as a critique of linear causality and reductionist science (see Von Bertalanffy, 1972; Cilliers, 1998; Levin, 1999). Many managers and scholars alike have noted that outcomes (such as reduced flows or inadequate water supply) cannot be attributed to a single factor alone but rather represent a complex interaction of socio-economic, ecological and political factors. At the heart of this critique was the concern that such linear thinking had - and continues to - influence management and governance. In challenging this, scholars point out that sustainability remains an elusive vision and that linear, conventional thinking has not only failed to chart a sustainable path but has, in many cases, actually contributed to the problem (Holling and Meffe, 1996; Walker and Salt, 2006).

It has been pointed out that natural and social systems are complex in their own right and that additional complexity is added by their interactions. A number of authors note that this poses particular challenges for disciplinary approaches (the so-called 'silo' approach) which may appear to work at first but are soon undermined by other factors that have received inadequate attention (see Berkes et al., 2003). Indeed, some assert that they cannot be understood, let alone managed, through conventional disciplinary approaches (Jasanoff et al., 1997; cited in Berkes et al., 2003). This is because the phenomena that we experience, or see, are reflections of multiple, diverse and distributed (scalar) causes. These attributes essentially describe complex systems, hence leading us to the 
assertion that complex systems thinking must underscore water resource management. Although a detailed review is beyond the scope of this paper, it can be noted that a complex system can be distinguished from a simple one, albeit complicated, by a number of attributes including non-linearity, uncertainty, emergence, scale, self-organisation and feedback loops (Table 1). Acknowledging these means accepting both their implications and lessons for future action (Berkes et al., 2003).

But what does this mean in practice? The essence of these systems is their inherent variation in space and time. This is what determines the system function and importantly, is what can add variation and novelty (i.e. they adapt). Gradually we are getting better at understanding and managing such attributes. Importantly, we strive to see the system holistically, with all systems as sub-systems of bigger systems, and invariably interacting with other sub-systems and the bigger and smaller systems to which they relate. Berkes et al. (2003) assert that there are three fundamental implications for resource management of accepting complexity:

- Models and perspectives based on linear thinking are inadequate (including optimisation models)

- Qualitative analysis is an important complement to quantitative approaches

- A multiplicity of perspectives is needed to analyse and manage complex systems.

There are a number of ways of dealing with uncertainty and complexity (Biggs, 2008):

- Strive to get as many people as possible thinking holistically about the system (biophysical, socioeconomic and institutional) and events

- Scenario-based planning (aided by mathematical and computer simulation and statistical analyses if necessary) can help one plan and account for random events

- Be prudent when making decisions ensuring that there are buffers to absorb surprises
- Employ adaptive management which seeks to 'learn-bydoing' so that the direction can be adapted as new information becomes available

- Recognise that in complex systems there are a number of ways to arrive at the same endpoint.

\section{Catchment management strategies - A framework for IWRM}

In South Africa, the intentions of the National Water Policy for South Africa (1997) and the Act are captured in the slogan 'some, for all, for ever, together.' This summarises the intention of redress underscored by two principles that are the foundations of the Act: equity and sustainability. Both the National Water Policy and Water resource Strategy also recognise the important of efficiency in use (detailed in Box 2). These principles are to be given practical meaning through the strategic planning process that comprise the catchment management strategies, and that we now outline.

In South Africa, catchment management strategies, which are a legislative requirement, offer the opportunity to plan for complexity and to manage this through a strategic, adaptive process that embraces learning informed by practice (DWAF, 2004 a). We will focus on how this is approached so as to achieve both sustainability and equity, but first the framework that guides the development of catchment management strategies is presented.

For this country, a vital component of IWRM is the progressive devolution of responsibility and authority over water resources to catchment management agencies, or CMAs, which will have jurisdiction over water management areas (DWAF, 1998). In terms of the NWRS, 19 water management areas have been delineated in South Africa (Fig. 1), although these may be amalgamated. The CMAs are in various stages of establishment. The Act requires that a CMS must be developed for each of the Water Management Areas and states: 'A catchment management strategy is the framework for water

\begin{tabular}{|c|c|}
\hline \multicolumn{2}{|c|}{$\begin{array}{c}\text { TABLE } 1 \\
\text { Key attributes of complex systems }\end{array}$} \\
\hline Attribute & Example \\
\hline $\begin{array}{l}\text { Socio-ecological systems are heterogeneous, dynamic and in } \\
\text { a state of flux. } \\
\text { Variability is essential and not a 'management inconvenience or } \\
\text { problem'. }\end{array}$ & $\begin{array}{l}\text { Rainfall may vary around an 'average' of } 500 \mathrm{~mm} \text { per year - } \\
\text { from } 200 \mathrm{~mm} \text { in a dry year to } 800 \mathrm{~mm} \text { in a wet year. This brings } \\
\text { about different effects each year and cumulatively. }\end{array}$ \\
\hline $\begin{array}{l}\text { Systems have multiple drivers, many of which are non-linear } \\
\text { in their effects and which operate at different scales. Hence out- } \\
\text { comes are usually not entirely predictable. Also some of these } \\
\text { drivers may relate to other 'sub-systems' such as a political or } \\
\text { global drivers. }\end{array}$ & $\begin{array}{l}\text { A reduction in base flows may reflect increased abstraction, the } \\
\text { impacts of a weir and a political decision to expand agriculture, } \\
\text { such as biofuels which are seen as a way to improve our foreign } \\
\text { exchange }\end{array}$ \\
\hline $\begin{array}{l}\text { Components of systems are independent and interacting and } \\
\text { understanding the linkages is important. In particular feedback } \\
\text { loops are an important attribute of complex systems. }\end{array}$ & $\begin{array}{l}\text { For example, a reinforcing loop is evident when wetland health } \\
\text { improves, causing an increase in the water table which causes } \\
\text { a further improvement in wetland health (Pollard and Perret, } \\
\text { 2007) }\end{array}$ \\
\hline $\begin{array}{l}\text { Multiple drivers and feedback loops often mean uncertainty } \\
\text { because we can't predict exact outcomes, Moreover they can } \\
\text { lead to unexpected outcomes }\end{array}$ & $\begin{array}{l}\text { The global drive to reduce dependence on fossil fuels (viewed } \\
\text { as a favourable position for sustainability) has increased biofuel } \\
\text { initiatives which are impacting on water resources and on food } \\
\text { availability. }\end{array}$ \\
\hline Complex systems display lags & $\begin{array}{l}\text { We are unlikely to see immediate benefits from the policy to } \\
\text { determine environmental flows because of the complex socio- } \\
\text { economic and political arrangements needed to achieve this }\end{array}$ \\
\hline $\begin{array}{l}\text { Complex systems are not necessarily complicated; in fact, they } \\
\text { often only have a basic set of drivers and responses. }\end{array}$ & $\begin{array}{l}\text { For example, fire, rainfall and fire management may be the key } \\
\text { drivers of savannah eco-systems. }\end{array}$ \\
\hline
\end{tabular}


resource management in a water management area. The NWRS provides the framework within which all catchment management strategies will be prepared and implemented in a manner that is consistent throughout the country'. One of the first functions of water resource management to the CMA will be the development of a CMS, described in Box 3. Indeed, the NWA states (Section 8): A catchment management agency contemplated in Chapter 7 must, by notice in the Gazette, establish a catchment management strategy for the protection, use, development, conservation, management and control of water resources within its water management area.' The following section provides an overview of the framework that sits at the core of these guidelines (DWAF, 2007 a), which also cover issues of policy requirements, roles and responsibilities, sequence and procedure and public participation (see Du Toit and Pollard, 2008).

Strategic planning is needed to honour our commitment to change. With the potential to create shifts, strategies have immense power in that they shape how things can - and will - be done. In South Africa this means explicitly addressing the transformation ideals of achieving equity and sustainability. Strategies should set the scene and ask the questions: what does this mean? And,what can be done about it? For example, a particular strategic approach is required to bring about equitable water allocation to ensure that the available water is used to reduce the current gap in equity. The guidelines define a catchment management strategy as a set of medium- to long-term action programmes to support the achievement of sustainability, equity and efficiency through integrated water resource management. They should complement policy and be given effect through detailed plans.
The CMS comprises a suite of sub-strategies which provide the basis for business and operational plans. Importantly however, whilst strategies will differ between WMAs so as to reflect their different priorities, there are certain core strategies, or clusters of strategies, that must be included. Secondly, strategy development is a strongly iterative process and they will evolve as CMAs assume more responsibilities and as they learn. Thus not all issues can be developed as part of the first strategy. Thirdly, different components of the CMS will be developed at different scales of space and time; for example, different approaches may be required for different sub-catchments. In order to avoid confusion that this can create these scales, which must be meaningfully and appropriately selected, must be made explicit.

In view of the legislative requirements, an overall framework for a CMS was developed (Fig. 2). Integrated water resource management in South Africa is conceptualised as four clusters Parts A to D - of information and strategies, which collectively comprise the strategy. A number of these deal specifically with the 'business' of IWRM whilst others facilitate the operation of the CMA and the strategies. This does not imply that no further strategies are needed; they represent what have been called the core sub-strategies. Notably, the clusters are not necessarily sequential, although certain priorities exist in respect of some clusters being conducted earlier that others (e.g. Part A; see also Chapter 4 of the Guideline).

\section{Part A: Important foundational information}

Part A does not involve strategy development per sé but provides the foundation for strategic action. The tenet is that no

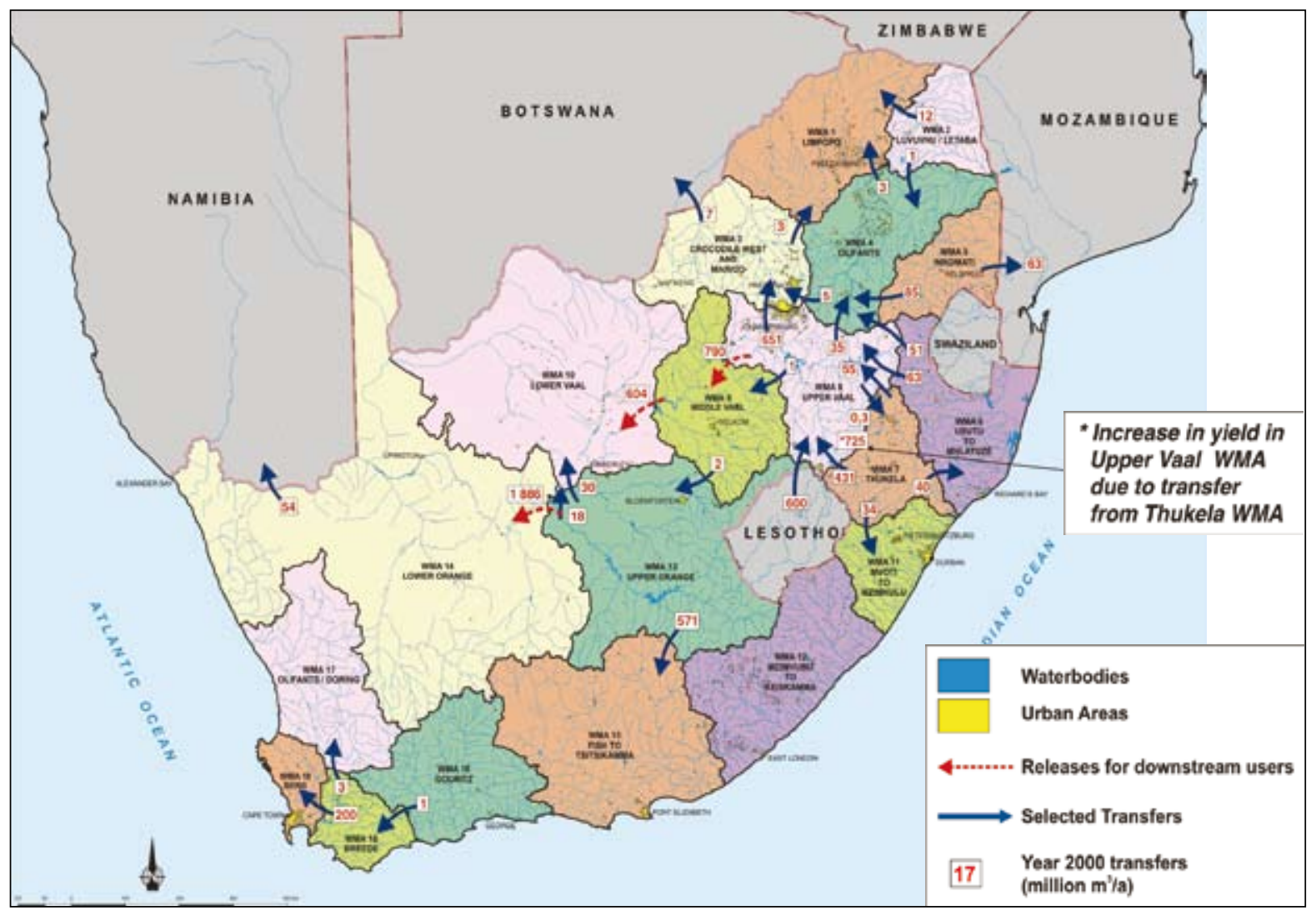

Figure 1

Map of South Africa showing the 19 water management areas (WMAs). Note that the amalgamation of these into between 7 and 9 WMAs is under consideration. Arrows indicate inter-basin transfers. 


\section{Box 2: Founding principles guiding the catch- ment management strategies in South Africa (see DWAF, 2004a; 2007a)}

The two founding principles that run throughout all policies and legislation associated with water resource management, namely sustainability and equity, are outlined below.

- Sustainability: Over the past few decades we have increasingly come to understand the interdependence between humans and ecosystems. Thus we now recognise that the more we compromise the quality and quantity of available water, the more we compromise our own livelihoods. Moreover, our obligation to protect the natural environment must take into account the needs of future generations as well. Thus, since ecological and socioeconomic sustainability depend on water resources, this should be a guiding principle evident in all allocation decisions.

- Equity: Historically, meaningful access to water lay in the hands of a minority of South Africans. With democratisation, a cornerstone of transformation is the need to ensure that this situation is reversed so that all South Africans share in our water resources (see also WSA, 1997). Equity implies fairness in meeting social, economic and environmental needs (DWAF, 1997). Equally, the imperative to fair access is also true for neighbouring countries with which we share rivers.

The White Paper and National Water resource Strategy also makes specific reference to efficiency which is an important aspect in achieving the founding principles.

- Efficiency/optimal beneficial use: Given that our water resources are limited and limiting, it is essential that we use them efficiently and in the best interests of all our people. Thus, the allocation of water to users should be guided by the need to encourage and support efficient, optimal and beneficial use of water.

adequate planning can be undertaken without an understanding of the current and projected situation in the WMA. In essence, Part A comprises a holistic assessment of both the status quo and of the potential future scenarios against:

- Water availability

- Requirements (reconciliation)

- The vision for the WMA.

Indeed, the vision is the cornerstone of the strategy since this provides the overarching strategic intent. Based on an understanding of the current situation and potential future directions, a stakeholder vision is defined. The vision must address the interrelated objectives of sustainability and equity because the subsequent strategies, particularly those described in Part B, give effect to this intention (DWAF, 2004 a, Ch. 3).

\section{Part B: Water resource management sub- strategies}

Once a vision has been set for a WMA, two key, complementary strategic areas, known as Resource Directed Measures (RDM) and Source Directed Controls (SDC), have been identified by the NWRS to achieve the vision. Collectively, these are the key, overarching strategies for IWRM in South Africa (DWAF 2003 b, 2004 b-e, DWAF and DFID 2004, DWAF 2005 a-c, 2006 a,b). The RDM are directed at protecting the water resources base by setting objectives for the desired condition of resources, and collectively this comprises Classification, the Reserve and Resource Quality Objectives. These measures focus on the quality of the water resource itself. Resource quality means the overall condition of the water resource (including quantity and quality) of instream and riparian habitats and aquatic biota. The SDC are measures to control water use to limit impacts to acceptable levels, as defined through RDM, These measures contribute to defining the limits and constraints that must be imposed on the use of water resources to achieve the desired level of protection. 'Water use' refers to all 11 uses defined in the Act. The SDC cannot be undertaken without RDM and vice versa. These strategies apply to both surface water and ground water resources, and to issues of quantity and quality.

\section{Part C: Facilitating sub-strategies}

The facilitating strategies are not directly linked to IWRM. Rather they are the 'oil' that keeps the 'engine' of IWRM going. In other words, without strategic plans for stakeholder engagement and communication (DWAF, undated; DWAF and RSA, 2003, and see Du Toit and Pollard, 2008)), information management and monitoring, and finances (DWAF, $2006 \mathrm{c}$; b), the intentions of IWRM cannot be achieved.

\section{Part D: Integration strategy - the need for co-operative governance}

As is well recognised by now, IWRM requires collaboration (see for example GWP 2002; Motteux, 2003; Burt, 2005). The inter-

\section{Foundational Information for the CMS}

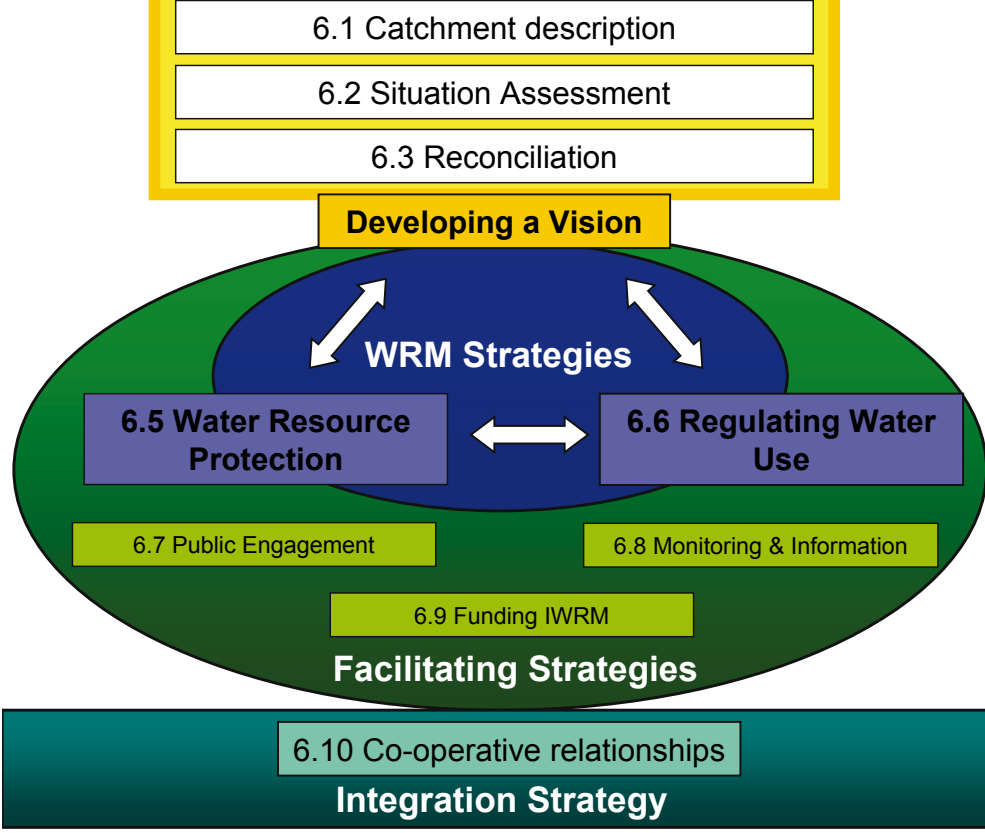

Figure 2

The framework for IWRM and hence the CMS in South Africa (from DWAF, 2007; adapted from DWAF, 1999). Clusters of contextual information and sub-strategies for the CMS fall into four parts: $A, B, C \& D$.

It is important to note that this framework does not suggest that the steps of IWRM are sequential. Rather much of the process is iterative. 
Box 3: Requirements for issues to be addressed by the catchment management strategies (Chapter 2, NWA, 1998; from DWAF, 2007 a)

A CMS must:

a. take into account the class of water resources and resource quality objectives contemplated in Chapter 3 , the requirements of the Reserve and, where applicable, international obligations;

b. not be in conflict with the NWRS;

c. set out the strategies, objectives, plans, guidelines and procedures of the CMA for the protection, use, development, conservation, management and control of water resources within its WMA;

d. take into account the geology, demography, land use, climate, vegetation and waterworks within its WMA;

e. contain water allocation plans which are subject to $S 23$, and which must set out principles for allocating water, taking into account the factors mentioned in S 27(1);

f. take account of any relevant national or regional plans prepared in terms of any other law, including any development plan adopted in terms of the Water Services Act, 1997 (Act No. 108 of 1997);

g. enable the public to participate in managing the water resources within its water management area;

h. take into account the needs and expectations of existing and potential water users; and

i. set out the institutions to be established.

linkages described above signify that multiple institutions are involved with various aspects of water-related activities, either directly or indirectly (see for example DWAF, $2003 \mathrm{a} ; \mathrm{c}$; d). Other strategic planning processes either have to be aligned (e.g. relevant municipal planning processes such as the integrated development plans and water services development plans; the sectoral plans such as water conservation \& demand management plans) or at least considered. The latter may include the public sector planning such as the provincial growth and development strategies, which may cut across water management areas, as well as ASGI-SA and private sector plans (e.g. mining and development). Moreover, given our international agreements, such as those governing the Limpopo, Inkomati and Orange River systems for example, the imperative for collaboration extends beyond our national borders. Therefore the CMA must set out strategic plans for ensuring integration and this strategy is effectively the 'glue' that holds IWRM together.

At the time of writing the development of certain key policy instruments was still underway. These include, amongst others, the classification system (DWAF, 2006 b), the Water Allocation Reform Process (DWAF, 2004 e; 2005 c) and the National Water Resource Information Management Service (DWAF et al., 2004).

\section{Achieving equity and sustainability in a complex environment}

As mentioned, the cornerstones of the Act that set the strategic direction for IWRM in South Africa are equity and sustainability. A $3^{\text {rd }}$ principle that is often quoted - that of efficiency - is raised in both the White Paper and the NWRS. This is an important precept and objective for water resource management in that it is one of the instruments for achieving equity and sustainability. This is explicitly recognised in the call for each sector to develop water conservation and water demand plans (see DWAF, 2004 a; c; d). Nonetheless, as a concept it requires careful thought and definition since interpretations can vary between water-use efficiency and economic efficiency (the latter is mentioned in the WSA and both are referred to in the NWRS). With CMAs and other water service institutions being required to recover costs, the objective of economic efficiency may undermine the intentions of sustainability and equity. In keeping with the intentions of the NWA, the following discussion focuses on the first of these two principles.

The strategic path to achieving equity and sustainability lies not in one sub-strategy alone but in the expression of these as cross-cutting themes throughout a catchment management strategy. This is consistent with managing in complex systems as described above where outcomes reflect the consequences of multiple factors and moreover, because they are not entirely predictable, we need to adapt as we learn. The catchment management strategies - if collaboratively, judiciously and thoughtfully developed, are examples of planning and managing in complex environments. Both of these principles rely on the whole - the collective effort of all the aforementioned sub-strategies - rather than simply on a single strategy. For example, it is easy but naïve to assume that equity will be achieved through compulsory licensing or water allocation reform alone. Similarly, sustainability cannot be achieved simply through the development of a Reserve determination or the determination of a class, but must be addressed through the synergies of various sub-strategies. An example of this is given in Fig. 3. Central to the development of a CMS is the vision, which is required to address both principles through the creation of a desired long-term view for the water resources that captures the idea of sustainable development and equity (DWAF, 2004 a).

Thus whilst sustainability is colloquially - and sometimes somewhat crudely - interpreted as 'water resource protection', and technically may be centrally 'held' within the RDM substrategy, it is a principle that underscores our approach to IWRM. Hence the assessment of the current and future situation must take into consideration the 'status' of sustainability of the catchment in question, by asking - 'is this a sustainable situation?' - and then to plan accordingly. The assessment clearly calls for a holistic approach, using sustainability criteria (amongst others; see for example those developed by Pollard et al., 1998; also in DWAF, 2007 a). These criteria should be fed into the monitoring strategy as resource quality objectives. For example, if the Reserve is regarded as a benchmark for sustainability, then this can serve as a criterion for assessing the current condition of the river as well as for future monitoring.

Once the desired future state of water resource protection has been described (in the vision) and set (for example through classification and a Reserve), it is essential to remember that there are a range of other strategies and plans required to give effect to this (see Fig. 3). Importantly, water use must be regulated to achieve this vision of protection so that sustainability can be ensured. This is given depth and meaning through the substrategy on Source Directed Controls including for instance, the water allocation plan and the conditions of a water use licence.

Equally, various sub-strategies and tools exist to collectively address the commitment to redress and equity. Again, whilst these are centrally 'held' by the SDC sub-strategies for wateruse authorisation and licensing, this principle runs through the entire strategy. These tools, some of which are still being developed, include Schedule 1, 'General Authorisations and Compulsory Licensing', which are included in the Act, as well as the Water Allocation Reform Programme. Other mechanisms include financial incentives/subsidies for emerging farmers and support for augmentation options (e.g. rainwater collection). 
Figure 3

Achieving sustainability and equity relies on the collective influence of numerous sub-strategies, as is illustrated by this example for sustainability. This principle, whilst being 'held'

centrally under resource directed measures, can only be achieved by drawing on various aspects of IWRM

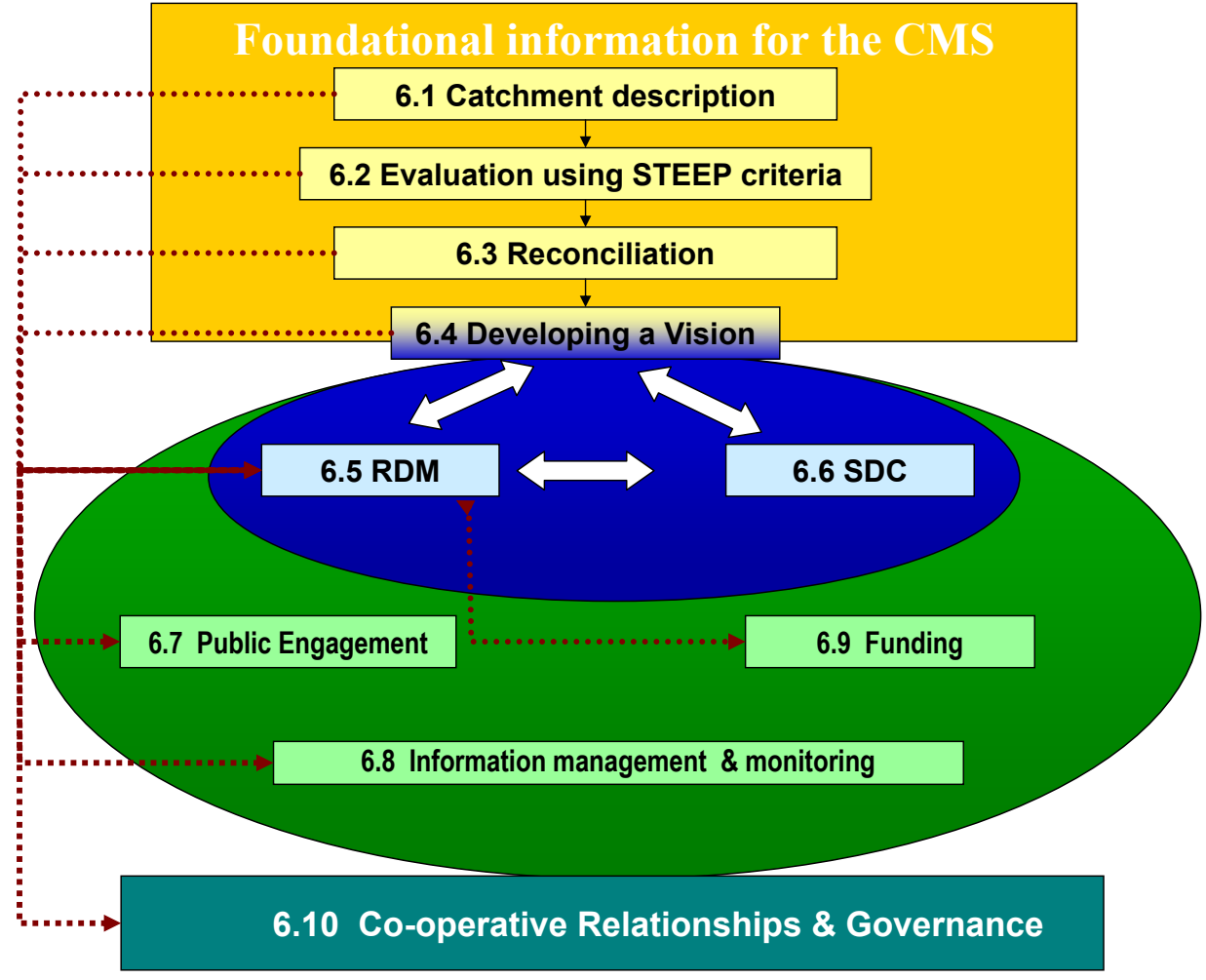

The basis for equity is provided by the situation assessment and visioning. The former requires an assessment based on criteria pertaining to equity; the latter requires a vision that talks to equity, redress and transformation (DWAF, 2004 a). Additionally, the ideal of securing water for basic human needs is provided for by the Basic Human Needs Reserve that is part of resource directed measures. While the principle of equity aims to adjust the imbalances and inequities of decades of skewed water access it is unlikely to adequately emphasise the need to provide water for the most vulnerable groups in society. The CMA has a central role to play, essentially through the CMS, to ensure that special attention is given to water for vulnerable and poor members of society (see Schreiner \& Van Koppen, 2002).

Multiple stakeholder platforms and plans for engaging the public are also important means for addressing both equity and sustainability through democratic decision-making processes. Equally, monitoring, finances and co-operation are all essential components for achievement of these goals. It is also imperative to stress that these strategies are not developed in a vacuum. Failure to recognise this has led to some surprises and unintended consequences (see for example Pollard et al., 1998). In a strategic planning environment there are planning processes that both contribute to the success of the CMS, and/or are potentially affected by the CMS. These will have to be aligned or at least considered (see Part D, above). These are not linear, but are linked and they have serious economic, political and social mandates which will have to be accounted for in some way.

\section{Conclusion}

We suggest that the NWA and related policy documents provide an enabling environment for planning and managing water resources in complex environments. The catchment management strategies - if collaboratively, judiciously and thoughtfully developed - are demonstrations of how key strategic plans can be designed to achieve equity and sustainability within such an environment. Essentially the above discussion demonstrates that the strategies are designed to manage in complex environments by acknowledging that multiple drivers, multiple outcomes and feedback loops are all realities (see Table 1). Moreover, because outcomes are unpredictable and lags are to be expected, the process is iterative based on learning and reflection. In this regard each strategy must be reviewed every five years so as to build on new information, experience and learning.

The development of catchment management strategies is driven by principles (not content alone) and we suggest that these, namely equity and sustainability, help one to 'keep an eye on the ball' and to navigate difficult issues that emerge in complex systems in a flexible way. The importance of visioning and the development of options through scenarios offer important management tools that are well-recognised in complexity theory for accommodating change, as well as establishing a hierarchy of actions that can address the overarching principles. In complex systems, the users must be part of deriving management solutions since this is where and how they learn. If they are excluded, the 'system' does not learn and hence adapt to change and surprise. This is important given that different configurations of management and use can still achieve the overall vision of equity and sustainability (i.e. in complex systems different paths can lead to the same end point). Self-organisation and identity of stakeholders are all essential considerations for building a collective understanding and hence resilience in a system. Thus for example, in developing water conservation strategies, the agricultural sector not only develops a sense of ownership and identity but also contributes to achieving the vision through their own internal regulation. Finally the recognition of embeddedness (that actions do not exist within a vacuum) and the need to collaborate with other plans and processes - articulated through the need for co-operative governance and participation - are important aspects of building resilience within catchment systems. 


\section{Acknowledgements}

We gratefully acknowledge the efforts of both Mr. Johnny Beumer and Bill Rowlston (both formerly of the Department of Water Affairs \& Forestry, now with Ninham-Shands and Coastal \& Environmental Services, respectively). Without their continuous support and commitment to overseeing the writing of the Guidelines for Catchment Management Strategies this work would not have been possible. Dr Harry Biggs (SanParks) has made invaluable contributions to discussions on management in complex systems. Our co-authors of the Guidelines, $\mathrm{Mr}$ Y Reddy and Mr T Tlou are also acknowledged. We thank two anonymous reviewers for their comments.

\section{References}

BERKES F, COLDING J and C FOLKE (2003) Navigating Social-Ecological Systems. Cambridge University Press.

BIGGS H (2008) Personal communication. Scientific Services, National Parks Board (SanParks), Skukuza, South Africa.

BURT J (2005) A Strategy for Participatory Water Resources Management in the Kat River Catchment. IWR, Rhodes University Grahamstown. WRC Report No K9/1496. Water Research Commission, Pretoria, South Africa.

CILLIERS P (1998) Complexity and Postmodernism: Understanding Complex System. Routledge, London, New York.

DWAF (1997) White Paper on a National Water Policy for South Africa. Department of Water Affairs and Forestry, Pretoria.

DWAF (2003 a) Volume 1: Water Conservation And Water Demand Management - A Planning Framework for Catchment Management Agencies. DRAFT. Department of Water Affairs and Forestry, Pretoria, South Africa.

DWAF (2003 b) A Guideline To The Water Quality Management Component of a Catchment Management Strategy. WMQ Series No. MS 8.2, Department of Water Affairs and Forestry, Pretoria, South Africa.

DWAF (2003 c) Volume 2: Guidelines for undertaking a water conservation and water demand management situation assessment and development of a business plan within the water services sector. Department of Water Affairs and Forestry, Pretoria, South Africa.

DWAF (2003 d) Volume 3: Guidelines for Implementing Water Conservation and Water Demand Management within the Water Services Sector. Department of Water Affairs and Forestry, Pretoria, South Africa.

DWAF (2004 a) National Water Resources Strategy. Department of Water Affairs and Forestry, Pretoria.

DWAF (2004 b) Resource Directed Water Quality Management ( $1^{\text {st }}$ edn.) Management Instruments Series (Final Draft). Version 2.0, Department of Water Affairs and Forestry, Pretoria.

DWAF (2004 c) Water Resource Planning Systems Series, Sub-Series No WQP 14, Resource Directed Water Quality Management Policies: 1st Edition Management Instruments Series. Version 2, Department of Water Affairs and Forestry, Pretoria.

DWAF (2004 d) Guidelines for Water Conservation and Water Demand Management. Volume 1: CMA Planning Framework. Department of Water Affairs and Forestry, Pretoria.

DWAF (2004 e) A Toolkit for Water Allocation Reform: A Manual to Help Achieve Race and Gender Equity in Water Allocations. Department of Water and Forestry (DWAF), Pretoria.

DWAF (2005 a) Summary Policy on the Resource Directed Management of Water Quality. Version 2.29, Department of Water Affairs and Forestry, Pretoria.

DWAF (2005 b) The Development of a National Water Resources Classification System. Inception report, Department of Water Affairs and Forestry, Pretoria, South Africa.

DWAF (2005 c) A Draft Position Paper for Water Allocation Reform in South Africa. Towards a Framework for Water Allocation Planning. Discussion document. Draft, Department of Water Affairs and Forestry (DWAF), Pretoria.

DWAF (2006 a) Water Use Authorisation Redress Guideline. "An
Assessment Tool for Socio-Economic Redress and Equity." Department of Water Affairs and Forestry (DWAF), Pretoria.

DWAF (2006 b) A Draft Position Paper on the Development of a Water Resources Classification System (WRCS) (Draft discussion document). Department of Water Affairs and Forestry, Pretoria.

DWAF (2006 c) Waste Discharge Charge System. Implementation Strategy (Draft Version 3.2). Draft Department of Water Affairs and Forestry (DWAF), Pretoria.

DWAF (2007 a) Guidelines for the Development of Catchment Management Strategies: Towards Equity, Efficiency and Sustainability in Water Resources Management. ( $1^{\text {st }}$ edn.) By SR Pollard, D du Toit, J Reddy and T Tlou. Department of Water Affairs and Forestry, Pretoria, South Africa. Available from ww.dwaf.gov.za/documents/ other: catchment management.

DWAF (2007 b) Establishment of a Pricing Strategy for Water Use Charges in Terms of Section 56(1) of the National Water Act, 1998. A Pricing Strategy for Raw Water Use Charges. Department of Water Affairs and Forestry, Pretoria.

DWAF (Undated) Public Participation for Catchment Management Agencies and Water User Associations. Guide 4, Department of Water Affairs and Forestry (DWAF), Pretoria.

DWAF and DFID (2004) Guide to Determining the Lawfulness of Existing Water Uses. Department of Water Affairs and Forestry, Pretoria.

DWAF, GROBLER D C and NTSABA M (2004) Strategic Framework for National Water Resource Quality Monitoring Programmes. Report No. N/0000/REQ0204, Resource Quality Services, Department of Water Affairs and Forestry, Pretoria.

DWAF and RSA (2003) Guidelines on the Inclusion of Disadvantaged Groups in Community Participation Processes. Department of Water Affairs and Forestry (DWAF), Pretoria.

DU TOIT D and POLLARD SR (2008) Updating public participation in IWRM: A proposal for a focused and structured engagement with catchment management strategies. Water SA 34 (6) 707-714.

FOLKE C, CARPENTER S, ELMQVIST T, GUNDERSON L, HOLLING CS and WALKER B (2002) Resilience and sustainable development building adaptive capacity in a world of transformations. Ambio 31 437-440.

GLOBAL WATER PARTNERSHIP (2002) IWRM Tool Box: Sharing knowledge for equitable, efficient and sustainable water resources management. Global Water Partnership, Stockholm, Sweden.

GORGENS, A, PEGRAM G, UYS M, GROBICKI A, LOOTS L, TANNER A and BENGU R (1998) Guidelines for Catchment Management to Achieve Integrated Water Resources Management in South Africa. WRC Report No KV 108/98. Water Research Commission (WRC), Pretoria.

GUNDERSON LH, HOLLING CS and LIGHT SS (1995) Barriers and Bridges to the Renewal of Ecosystems and Institutions. Columbia University Press.

HOLLING CS 2000 Theories for sustainable futures. Conservation Ecology 4 (2). Online URL: “../.././vol4/iss2/art7”http://www.consecol.org/Journal/vol4/iss2/art7.

HOLLING CS (2001) Understanding the complexity of economic, ecological and social systems. Ecosyst. 4 390-405.

HOLLING CS, GUNDERSON LH and LUDWIG D (2002) In quest of a theory of adaptive change. Pp 3-22. In: LH Gunderson and CS Holling (eds.) Panarchy: Understanding Transformations in Human and Natural Systems. Island Press, Washington DC.

HOLLING CS and MEFFE GK (1996) Command and control and the pathology of natural resource management. Conserv. Biol. 10 328337.

JONES T, NEWBORNE P and PHILLIPS B (2006) Applying the Principles of Integrated Water Resource and River Basin Management - An Introduction. Report to WWF-Int.

KING J and BROWN C (2006) Environmental flows: Striking the balance between development and resource protection. Ecol. Soc. 11 (2) 26. [online] URL: http://www.ecologyandsociety.org/vol11/iss2/ art26/

KINZIG PA, CARPENTER S, DOVE M, HEAL G, LEVIN S, LUBCHENCO J, SCHNEIDER SH and STARRETT S (2000) Nature and society: an imperative for integrated environmental research. 
LEVIN SA (1999) Fragile Dominion: Complexity and the Commons. Massachusetts Helix Books, Cambridge.

McKAY H (1996) The philosophy and practice of Integrated Catchment Management: Implications for Water Resource Management in South Africa. Discussion Document. WRC Report No TT 81/96, Department of Water Affairs and Forestry (DWAF), Water Research Commission, Pretoria, South Africa.

MOTTEUX N (2003) Guidelines for Participatory IWRM. WRC Report No K5 1233/0/1.Water Research Commission, Pretoria.

MUNRO B (1995) Water for Sustainable Development in Africa. Discussion paper (Expert Group Meeting on the Implications of Agenda 21 for Integrated Water management in Africa).

PENNING DE VRIES FWT, ACQUAY H, MOLDEN D, SCHERR SJ, VALENTIN C and COFIE O (2002) Integrated Land and Water Management for Food and Environmental Security. Comprehensive Assessment Secretariat, Global Environment Facility, International Water Management Institute (IWMI), Colombo, Sri Lanka.

POLLARD SR, PEREZ DE MENDIGUREN JC, JOUBERT A, SHACKELTON CM, WALKER P, POULTER T and WHITE M (1998) Save the Sand: Phase 1. Feasibility Study: The Development of a Proposal for a Catchment Plan for the Sand River Catchment. Department of Water Affairs and Forestry; Department of Agriculture and Land Affairs.

POLLARD SR and PERRET S (2007) Investigating Interactions between Biophysical Functioning, Usage Patterns, and Livelihoods in a Wetland Agro-Ecosystem of the Sand River Catchment Through Dynamic Modeling. Draft Report to the Challenge Programme on Food and Water.

REPUBLIC OF SOUTH AFRICA (1997) The Water Services Act. Act No. 108 of 1997. Government Gazette. RSA.

REPUBLIC OF SOUTH AFRICA (1998) The National Water Act. Act No. 36 of 1998. Government Gazette. RSA.

SCHREINER B and VAN KOPPEN B (2002) Catchment management agencies for poverty eradication in South Africa. Phys. Chem. Earth 27 969-976.

VON BERTALANFFY L (1972) The History and Status of General Systems Theory. The Academy Manage. J.15(4)407-426. URL: http:// www.jstor.org/stable/255139 .

WALKER B and SALT D (2006) Resilience Thinking: Sustaining Ecosystems and People in a Changing World. Island Press, Washington DC. 